\title{
On the Primary Phase Microstructure of Solidifying Ti-46Al-8Nb Refractory Intermetallic Alloy
}

\author{
A. V. Kartavykh \\ Dept. for Functional and Structural Nanomaterials, Technological Institute for Superhard and Novel Carbon Materials (TISNCM), \\ Troitsk, 142190, Russia
}

\begin{abstract}
The reported contradictory data on microstructure formation of the refractory intermetallic Ti-46Al-8Nb (at.\%) alloy and on the high-temperature phase transformations proceeding within the $\mathrm{Ti}-\mathrm{Al}-\mathrm{Nb}$ phase diagram are analysed and clarified experimentally. To determine the primary solidifying phase, a set of experiments is performed on melting of the alloy specimens with low oxygen contamination in a high purity argon atmosphere using crucibles made of oxygen-free ceramics $(99.99 \%$ AIN), and subsequent rapid solidification. Volumetrically-isothermal cooling from $1943 \mathrm{~K}$ at rates of 5, 10, and $20 \mathrm{~K} / \mathrm{s}$ and following quench of mini-ingots from $1763 \mathrm{~K}$ are used. Specimens were studied by scanning electron microscopy (SEM) in backscattered electron (BSE) mode. SEM-BSE micrographs demonstrate contrasting shadow regions of non-uniform niobium segregation, which are fixed by quench and decorate the primary polycrystalline microstructure formed within the temperature range between 1843 (liquidus) and $1773 \mathrm{~K}$ (solidus). The primary crystallizing phase is proven to be represented by $\beta(\mathrm{Ti})$ dendrites, which have clearly pronounced fourfold ( $b c c$-lattice) symmetry being formed with secondary dendrite arms development. The solidification path is shown to be described with singlephase scheme $\mathrm{L} \rightarrow \mathrm{L}+\beta(\mathrm{Ti}) \rightarrow \beta(\mathrm{Ti})$; no peritectic $\beta(\mathrm{Ti}) \rightarrow \alpha(\mathrm{Ti}) b c c-h c p$ phase transformation revealed within the mushy state of alloy.
\end{abstract}

Keywords Tial-Based Intermetallics, Phase Diagrams, Solidification, Microstructure, Electron Microscopy (SEM)

\section{Introduction}

The lightweight intermetallic $\mathrm{Ti}-46 \mathrm{Al}-8 \mathrm{Nb}$ (at.\%) alloy is a new advanced material for the application in constructions and items operating under extreme high temperature and high pressure gas-plasma medium conditions. In particular in the EU countries, the alloy has received a major attention in developing pilot technologies of turbine blades manufacturing for gas-burning power plants and aero-engines within IMPRESS Integrated Project[1]. In contrast to most of TiAl-based alloys, the $\mathrm{Ti}-46 \mathrm{Al}-8 \mathrm{Nb}$ is characterized by the improved combination of ductility and high-temperature impact strength that is reached via the formation of a special phase polycrystalline microstructure of ingot or functional cast item[2]. The purposeful formation of a reproducible balanced dual-phase $\gamma+\alpha_{2}$ structure, which is additionally strengthened with niobium alloying and characterized by optimum dimensional and orientational grain parameters, is rather difficult problem[3,4]. During casting and cooling, the alloy undergoes successive multistage structural and phase transformations (including those in solid state), which are reflected in its complex phase diagram. Purposeful

* Corresponding author:

karta@korolev-net.ru (A.V. Kartavykh)

Published online at http://journal.sapub.org/materials

Copyright (C) 2012 Scientific \& Academic Publishing. All Rights Reserved microstructural engineering of $\mathrm{Ti}-46 \mathrm{Al}-8 \mathrm{Nb}$ alloy requires reliable temperature-phase state diagrams, at least, for close chemical composition ranges. However, there are a number of substantially different high-temperature $\mathrm{Ti}-\mathrm{Al}-\mathrm{Nb}$ triple phase diagrams, even in the reputable specialized handbooks (see, e.g.[5]). It follows from these diagrams that both the $\beta$, and $\alpha$ phases could be the primary crystalline phase for the Ti-46Al-8Nb (at.\%) composition (Figure. 1). It is highly crucial point, since these phases have different crystal lattices ( $b c c$ and $h c p$ ones[6], respectively) and, therefore, they form the primary polycrystalline grains differing in sizes and symmetry. It is likely that one of the causes for the difference in the reported data is the uncontrollable dissolved oxygen content in the TiAl-based alloys used for the experimental phase diagram evaluations. According to[7,8], interstitial oxygen substantially affects the composition and structure of the primary solid phase in TiAl intermetallics whose compositions are close to equiatomic with respect to the $\mathrm{Ti} / \mathrm{Al}$ ratio. To determine the fundamental solidification behaviour of the Ti-46Al-8Nb alloy more exactly, experiments should be performed under high purity conditions at reproducible temperature regimes using initial material minimally contaminated with oxygen. A primary microstructure cannot be revealed in industrially cast alloy owing to the diffusion averaging of the component concentrations and deep solidphase transformations occurring in massive cast items under slow cooling conditions. The problem can be solved by 
applying a special laboratory test furnace (stand) that allows performing the processes of controlled rapid solidification and subsequent quenching of small sample from temperature slightly lower then solidus (to fix the structure). According to recent data of [9], the distribution coefficients of niobium and aluminum in $\mathrm{Ti}-46 \mathrm{Al}$ system at the liquidus temperature are 1.154 and 0.923 , respectively. Therefore, the primary solid phase and inter-crystalline melt in mushy state should be enriched in niobium and aluminum, respectively. Areas characterized by a high niobium concentration exhibit a bright contrast in scanning electron microscopy (SEM-BSE) micrographs. Thus, the nature of decorated primary dendrites can be determined visually taking into account their symmetry, because the $\beta$ and $\alpha$ phases have four- and six-fold symmetry each, respectively. This approach was used in the present study aimed at experimental determination of the fundamental nature of the primary melt grown solid phase in the refractory $\mathrm{Ti}-46 \mathrm{Al}-8 \mathrm{Nb}$ alloy in order to eliminate the contradiction of the data on the phase transformations and structure formation during solidification and subsequent heat treatment.

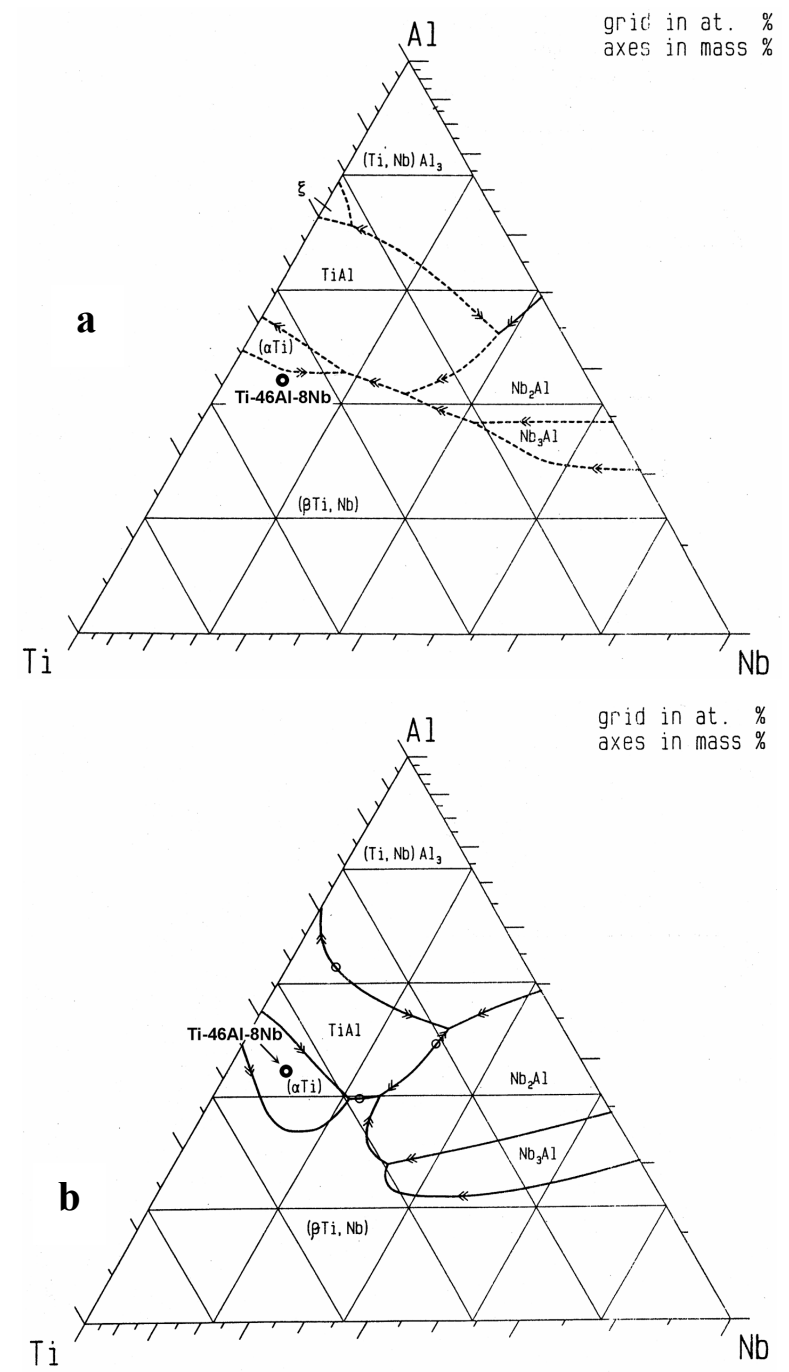

Figure 1. Liquidus surface projections for the ternary $\mathrm{Ti}-\mathrm{Al}-\mathrm{Nb}$ diagrams given in[5] in accordance with the data of (a) J.H. Perepezko and (b) U.R. Kattner. The alloy composition under study is marked by $(\circ)$ symbol

\section{Experimental}

The pilot batch of intermetallic alloy was produced by GfE Metalle und Materialien GmbH (Germany, Nuremberg, http://www.gfe.com) via direct synthesis using initial components and an induction furnace with a "cold" copper crucible, and subsequent triple homogenizing arc remelting (hereinafter, initial alloy GfE). In accordance with the manufacturer certificate, the oxygen content in the alloy is 520 wt.ppm and the real alloy composition corresponds to the $45.78 \mathrm{Ti}-46.35 \mathrm{Al}-7.87 \mathrm{Nb}$ (at.\%).

Our experiments were performed using a boat crucibles 2 $\mathrm{cm}^{3}$ in volume manufactured of AlN $99.99 \%$ purity by GIREDMET Ltd. (Moscow, Russia). The technique of TiAl-based intermetallics solidification/casting in AlN non-oxide crucibles/moulds to decrease the interstitial oxygen contamination in ingots was suggested, developed, and firstly performed in $[10,11]$ and was patented by us in[12]. We used technical argon subjected to triple purification, namely, drying of the gas in a silica gel column and the absorption of $\mathrm{O}_{2}$ and $\mathrm{CO}_{2}$ with zeolite filters. This gas refining procedure is a standard technology used in the semiconductor industry; the Ar purity was checked by the dew point of the gas; the latter did not exceed $-70^{\circ} \mathrm{C}$.

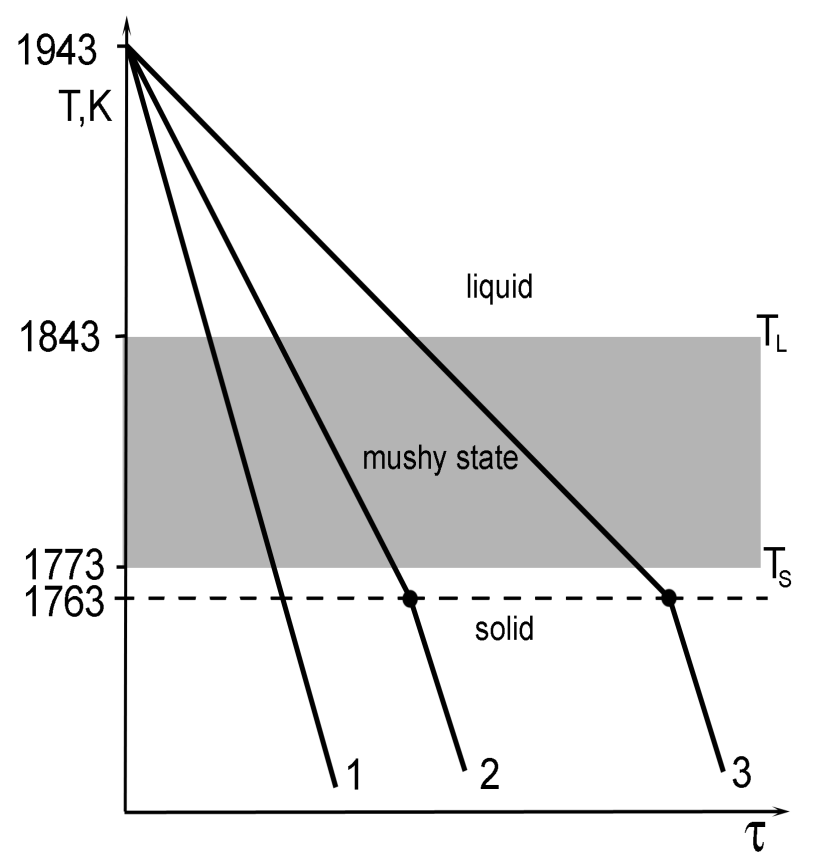

Figure 2. Schematic of experimental solidification/quench thermal cycles for specimens 1, 2 and 3 of Ti-46Al-8Nb (at.\%) alloy

Melting and re-solidification of TiAl-Nb alloy specimens were performed using the specialized electric furnace (laboratory benchmark stand) described in detail in $[11,13]$. The advances of the stand consist in low thermal inertia of the high-temperature unit, the possibilities to control and maintain the heating and cooling rates of samples under study over wide rate ranges, and the use of small volumes and masses of charged alloy and crucible to ensure a regime of a specimen heat treatment close to the volumetricallyisothermal one. 
The experimental cycle consists of the following stages: (1) heating of Ti-46Al-8 $\mathrm{Nb}$ sample $5 \mathrm{~g}$ in weight to $1943 \mathrm{~K}$ in a crucible (i.e. to the $100 \mathrm{~K}$ overheat above the equilibrium liquidus temperature[14]) at the rate of $120 \mathrm{~K} / \mathrm{min}$; (2) isothermal exposure of the melt for $5 \mathrm{~min}$; (3) rapid cooling to $1763 \mathrm{~K}$ at a rate of $d T / d \tau=20$ (sample 1), 10 (sample 2), or 5 $\mathrm{K} / \mathrm{s}$ (sample 3); and (4) final quenching within the temperature range $1763-673 \mathrm{~K}$ at the rate of $20 \mathrm{~K} / \mathrm{s}$. Controlled fixing quench of as-solidified microstructure was performed by a directed inert gas jet: the furnace heater was turned off while the argon flow rate simultaneously increased. For the sake of clarity the schematic of solidification/quench thermal cycle is given for each specimen in Figure. 2.

Scanning electron microscopic studies of sections (transverse vertical sections of three ingots withdrawn from boat crucibles after solidification) were performed using JSM6480LV device in backscattered electron mode. The sections were prepared using Buehler $\mathrm{GmbH}$ equipment and consumables. SiC bonded abrasive with a grain size of $5 \mu \mathrm{m}$ was used for grinding the sections surface; following polishing was performed in two stages using a soft pad and the suspension of synthetic diamond in surfactant solution with a particle size of $3 \mu \mathrm{m}$ and $1 \mu \mathrm{m}$. No chemical etching of the alloy sections was applied.

\section{Results and Discussion}

Figures 3a-3c show SEM-BSE micrographs taken from the polished sections of experimental $\mathrm{Ti}-46 \mathrm{Al}-8 \mathrm{Nb}$ specimens. The use of a progressively decreasing cooling rate $d T / d \tau$ and the decorating $\mathrm{Nb}$-alloying effect allowed us to trace the dynamics of the nucleation and morphological development of primary phase polycrystals. The liquidus $\left(\mathrm{T}_{\mathrm{L}}\right)$ and solidus $\left(T_{S}\right)$ temperatures of the alloy under study are known to be 1843 and $1773 \mathrm{~K}$, respectively[14]. This allows us to estimate the solidification time $\tau$ for each experiment. When cooling sample 1 at the rate $d T / d \tau=20 \mathrm{~K} / \mathrm{s}(\tau=3.5 \mathrm{~s})$, only an equiaxed granular primary microstructure characterized by grain sizes of $80-100 \mu \mathrm{m}$ (Figure. $3 \mathrm{a}$ ) has time to form as a result of multiple volumetric nucleation of the solid phase; no habit of grains has been formed yet. When cooling sample 2 at the rate $d T / d \tau=10 \mathrm{~K} / \mathrm{s}(\tau=7 \mathrm{~s})$, a dendritic primary phase structure forms as a result of competitive growth of polycrystalline grains; therewith, some dendrites even have the developed secondary arms (see Figure. 3b). Further morphological development of dendrites is observed in sample 3, where $d T / d \tau=5 \mathrm{~K} / \mathrm{s}$. In this case $(\tau=14 \mathrm{~s})$, the most clearly pronounced dendritic microstructure forms that characterized by a high degree of fourfold symmetry with developed arms of the second and even the third order (see Figure. $3 \mathrm{c}$ ). Since a dendritic crystal grows preferably along the thermal gradient direction, the most symmetric and developed dendrites, being characterized by a minimum deviation of cross-arms angle from $90^{\circ}$, form at the volumetrically-isothermal cooling conditions applied in the laboratory benchmark furnace.
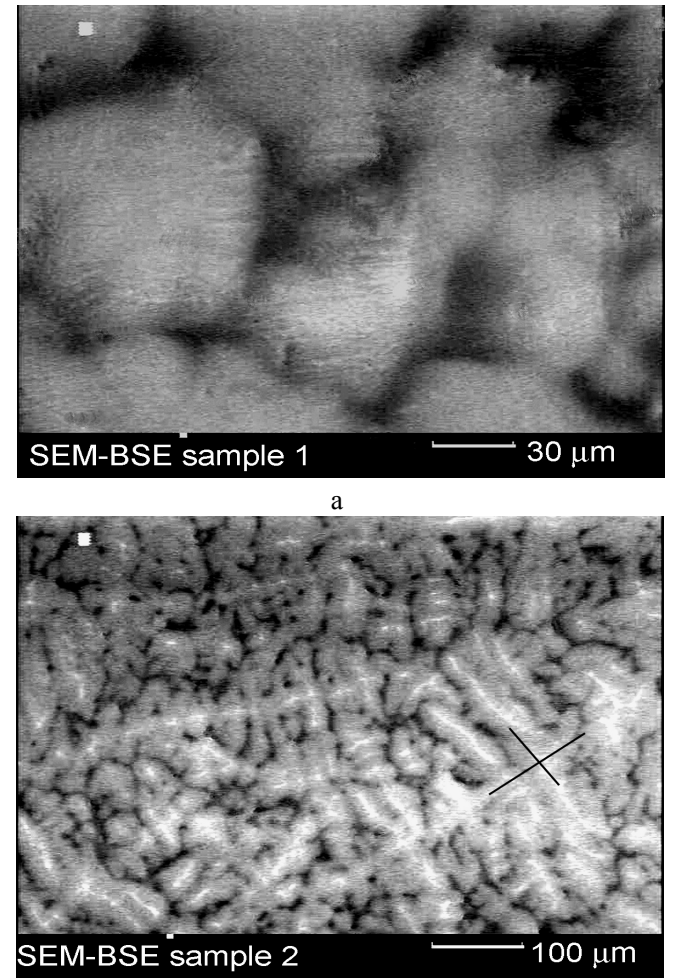

b

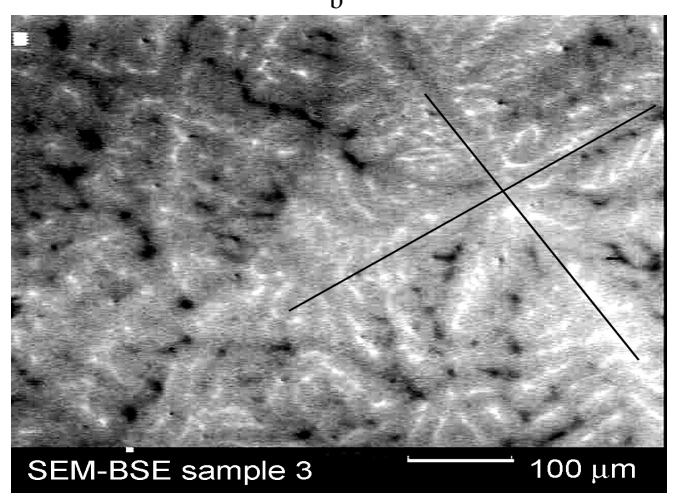

c

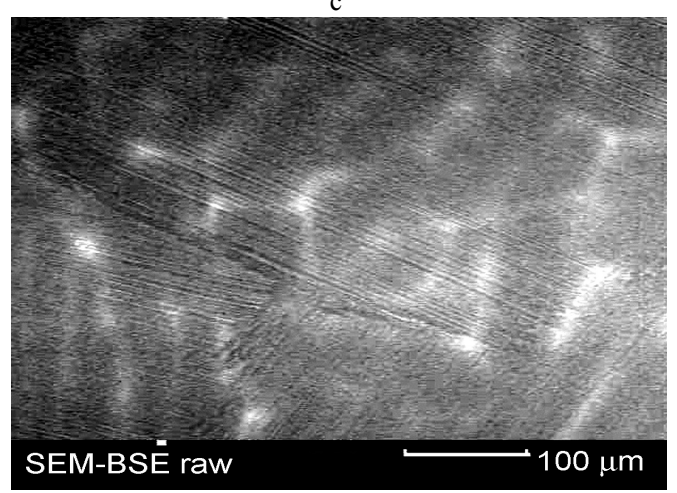

d

Figure 3. SEM-BSE micrographs of the primary microstructure contrast in $\mathrm{Ti}-46 \mathrm{Al}-8 \mathrm{Nb}$ alloy samples solidified at cooling rates of (a) 20, (b) 10 and (c) $5 \mathrm{~K} / \mathrm{s}$. Straight lines indicate the growth axes of primary and secondary $\beta(\mathrm{Ti})$-phase dendrite arms; the angle between them is close to $90^{\circ}$ and indicates the development of fourfold symmetry. (d) - Micrograph of structure of the initial GfE alloy batch prepared under slow cooling conditions. Alternating parallel lamellae of the intermetallic $\alpha_{2}-\mathrm{Ti}_{3} \mathrm{Al}(\mathrm{Nb})$ and $\gamma-\operatorname{TiAl}(\mathrm{Nb})$ phases, boundaries of lamellar colonies, and residual bright areas with higher niobium content are visible 


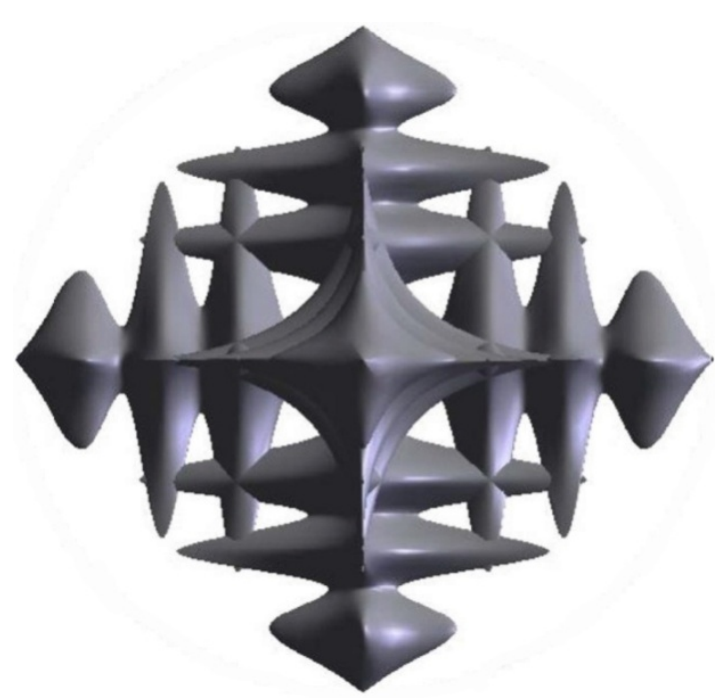

Figure 4. Idealistic theoretical shape of a dendrite solidified with the $b c c$ $\beta$ (Ti) lattice in accordance with the simulation data[15] (for comparison with the real dendrite shown in Figure. 3c)

The perfect fourfold symmetry of the most developed dendrites obtained experimentally (Figure. 3c) indicates the formation of the primary $\beta(\mathrm{Ti})$ solid phase. Moreover, their shape repeats adequately that of simulated ideal dendrite[15] solidified with the $b c c \beta(\mathrm{Ti})$ lattice (Figure. 4). According to available data, this fact agrees well with the phase transformation sequence for the Ti-46Al-8Nb composition in the isopleth calculated by Witusiewicz et al. [16] (Figure. 5a), and disagrees in principle with the analogous quasibinary phase diagram of Saunders [17] that given in Figure. 5b.

Note fundamental contradictions in determining the mechanisms of primary solidification in the near-peritectic single-phase alloy (Figure. 5a) and the peritectic alloy (Figure. $5 b$ ). In accordance with the aforementioned two phase diagrams, the initial GfE alloy prepared under slow cooling conditions should have a final dual-phase $\gamma+\alpha_{2}$ structure. Indeed, Figure. $3 \mathrm{~d}$ displays parallel alternating lamellae of the main intermetallic $\gamma-\mathrm{TiAl}(\mathrm{Nb})$ and $\alpha_{2}-\mathrm{Ti}_{3} \mathrm{Al}(\mathrm{Nb})$ phases. The lamellae result from solid state phase separation and form colonies inside the inherited boundaries of primary crystalline grains. Quantitative X-ray phase analysis of alloy specimens of the same pilot batch performed earlier in [10, 11] confirms the presence of only the basic intermetallic $\gamma$-TiAl(Nb) and $\alpha_{2}-\mathrm{Ti}_{3} \mathrm{Al}(\mathrm{Nb})$ phases, whose volumetric fractions are 0.85 and 0.15 , respectively. This quantitative phase relationship agrees better with the diagram by Witusiewicz in Figure. 5a. It follows notably from this figure that the $\mathrm{Ti}-46 \mathrm{Al}-8 \mathrm{Nb}$ (at.\%) alloy has a pro-peritectic composition and solidifies according to the simple single-phase reaction $L \rightarrow L+\beta(T i) \rightarrow \beta(T i)$; however, this composition is very close to the peritectic transformation range. As is seen from the diagram, a minimum increase in the aluminum content (only by $1-2$ at.\%) in the melt can lead to change of its solidification mechanism in accordance with the peritectic reaction $L \rightarrow L+\beta(T i) \rightarrow L+\beta(T i)+\alpha(T i) \rightarrow \beta(T i)+\alpha(T i)$ i.e., eventually, to the appearance of an additional primary crystalline high-temperature $\alpha(\mathrm{Ti})$ phase.

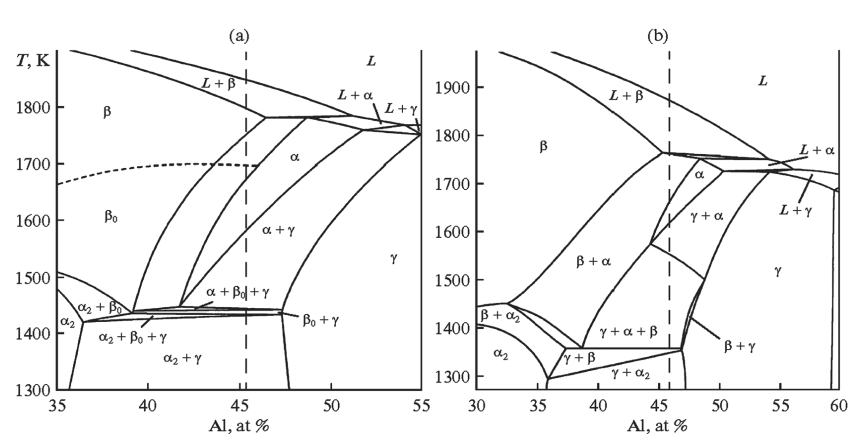

Figure 5. Calculated quasibinary sections (isopleths) of the ternary $\mathrm{Ti}-\mathrm{Al}-\mathrm{Nb}$ phase diagram for 8 at.\% $\mathrm{Nb}$ calculated in (a)[16] and (b)[17] using the CALPHAD and ThermoCalc software packages, respectively. The dashed line traces the sequence of thermal phase transformations in $\mathrm{Ti}-46 \mathrm{Al}-8 \mathrm{Nb}$ alloy

It is well known that $\alpha$-phase dendrites have characteristic sixfold symmetry (Figure. 6). In the presence of multiple centres of nucleation when solidify from peritectic compositions, $\alpha$-dendrites form in the melt spontaneously along with fourfold $\beta(\mathrm{Ti})$ dendrites $[9,18]$. In high-pure $\mathrm{Ti}-\mathrm{Al}$ melts (where independent nucleation is hampered), $\alpha(\mathrm{Ti})$ grains nucleate and develop on the surface of branched $\beta$ dendrites, the latter represent a so-called parent phase[19]. In any case, peritectic reaction changes the alloy microstructure via the formation of the dual-phase mixture of primary polycrystalline grains differing in the symmetry and sizes, and forming further the colonies of $\gamma$ and $\alpha_{2}$ lamellae in the course of subsequent solid-phase transformations within the inherited boundaries of each grain. These data indicate a high structural sensitivity of the alloy to local increases in the aluminum content (with respect to the nominal composition), which can occur (for a number of reasons) in melt in the course of its non-equilibrium bulk solidification. In our recent studies, this assumption was confirmed by numerical simulation and experimentally in performing directional solidification of the Ti-46Al-8Nb alloy. In particular, the kinetic effect of melt enrichment with aluminum ahead of solidification front is possible owing to aluminum segregation at the distribution coefficient of 0.923 (less than unity), while the melt hydrodynamics is too weak for composition-averaging mixing[20,21].

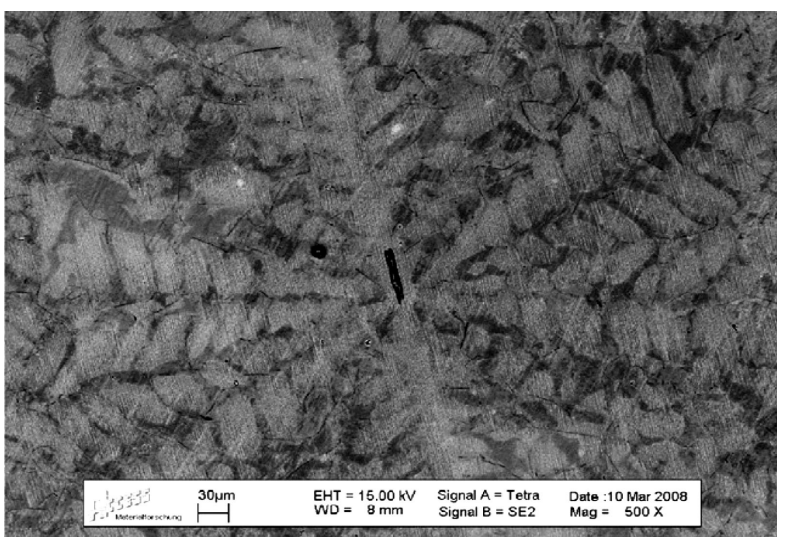

Figure 6. SEM-BSE micrograph of $\alpha(\mathrm{Ti})$-phase dendrite nucleated on $\mathrm{TiB}_{2}$ seed micro-particle (the latter is seen at the center of dendrite) during solidification of Ti-49Al-1B (at.\%) alloy[18] 
Presently it should be noted that, with allowance for a possible numerical inaccuracy of the phase field boundaries definition in the calculated isopleth[16], the fact of slightly pro-peritectic solidification path of the $\mathrm{Ti}-46 \mathrm{Al}-8 \mathrm{Nb}$ alloy cannot be considered as strictly determined. Nevertheless, no structural components having the sixfold symmetry were revealed in SEM-BSE micrographs of the alloy subjected to controlled solidification and quenching. This fact just confirms the absence of primary melt grown $\alpha(\mathrm{Ti})$ dendrites in the alloy structure and, by such the way, the principal correctness of the phase diagram shown in Figure. 5a.

\section{Conclusions}

(1) As a result of targeted experiments on controlled solidification and subsequent quenching of high-purity specimens and SEM studies, the nature of the primary crystalline phase in the intermetallic $\mathrm{Ti}-46 \mathrm{Al}-8 \mathrm{Nb}$ (at.\%) alloy was determined. It is shown that $\beta(\mathrm{Ti})$ dendrites, which have clearly pronounced fourfold symmetry, is the primary solid phase that forms within the liquidus-solidus temperature range.

(2) The solidification path of the alloy is shown to be described with single-phase scheme $\mathrm{L} \rightarrow \mathrm{L}+\beta(\mathrm{Ti}) \rightarrow \beta(\mathrm{Ti})$; no peritectic $\mathrm{L} \rightarrow \mathrm{L}+\beta(\mathrm{Ti}) \rightarrow \mathrm{L}+\beta(\mathrm{Ti})+\alpha(\mathrm{Ti}) \quad b c c-h c p$ phase transformation was revealed within the mushy state.

(3) In accordance with the experimental results, the phase diagram calculated by Witusiewicz et al. in Ref.[16] was selected from conflicting reported data. At present, it most correctly reflects the sequence of high-temperature phase transformations during solidification and successive cooling of the alloy under study.

\section{ACKNOWLEDGEMENTS}

This work was performed in terms of Federal program "Research and scientific-pedagogical brainpower of innovated Russia 2009-2013" (State contract no. 02.740.11.0505) and was supported by the Russian Foundation for Basic Research (grants 10-03-00338 and 12-01-97514).

\section{REFERENCES}

[1] D.J. Jarvis, D. Voss, "IMPRESS Integrated Project - An overview paper", Materials Science and Engineering A 413-414, pp. 583-591, 2005.

[2] http://ec.europa.eu/research/industrial_technologies/pdf/theexecutive-summary-of-impress-project_en.pdf

[3] Wu Xinhua, "Review of alloy and process development of TiAl alloys", Intermetallics 14, pp. 1114-1122, 2006.

[4] A. Lasalmonie, "Intermetallics: Why is it so difficult to introduce them in gas turbine engines?", Intermetallics 14, pp. 1123-1129, 2006.
[5] S. Gama, "Aluminum-Niobium-Titanium", in: G. Petzow and G. Effenberg (Eds.), Ternary Alloys: A Comprehensive Compendium of Evaluated Constitutional Data and Phase Diagrams. Vol. 7 (Al-Mg-Se to Al-Ni-Ta), VCH Verlagsgessellschaft, Weinheim, pp. 382-398, 1993.

[6] I. Ohnuma, Y. Fujita, H. Mitsui et al., "Phase equilibria in the Ti-Al binary system", Acta Materialia 48, pp. 3113-3123, 2000 .

[7] A. Huang. M. H. Loretto, D. Hu et al., "The role of oxygen content and cooling rate on transformations in TiAl-based alloys", Intermetallics 14, pp. 838-847, 2006.

[8] J. Zollinger, J. Lapin, D. Daloz and H. Combeau, "Influence of oxygen on solidification behaviour of cast TiAl-based alloys", Intermetallics 15, pp. 1343-1350, 2007.

[9] U. Hecht, D. Daloz, J. Lapin, A. Drevermann, V.T. Witusiewicz, J. Zollinger, "Solidification of TiAl-based alloys", in: M. Palm, B.P. Bewlay, M. Takeyama, J.M.K. Wiezorek, Y-H. He (Eds.), Advanced Intermetallic-Based Alloys for Extreme Environment and Energy Applications (Mater. Res. Soc. Symp. Proc. Vol. 1128), Warrendale, PA, 2009, 1128U03-01.

[10] A.V. Kartavykh, V.V. Cherdyntsev, "Chemical Compatibility of a TiAl-Nb Melt with Oxygen-Free Crucible Ceramics Made of Aluminum Nitride", Russian Metallurgy (Metally) 6, pp. 491-499, 2008.

[11] A.V. Kartavykh, V.V. Tcherdyntsev and J. Zollinger, "TiAl-Nb melt interaction with AlN refractory crucibles", Materials Chemistry and Physics 116, pp. 300-304, 2009.

[12] "Method for production of ingots and cast articles out of intermetallic alloys", Russian Federation patent no.2362651 (2009). Online http://195.208.85.248/Archive/PAT/2009FU LL/2009.07.27/DOC/RUNWC1/000/000/002/362/651/docu ment.pdf

[13] A.V. Kartavykh, V.V. Chinarov, "Bench for High-Temperat ure Material Testing and Its Application in Metallurgy of Refractory Intermetallics", Inorganic Materials 47, pp. 1649-1654, 2011.

[14] I. Egry, R. Brooks, D. Holland-Moritz, R. Novakovic, T. Matsushita, E. Ricci, S. Seetharaman, R. Wunderlich, D. Jarvis, "Thermophysical Properties of $\gamma$-Titanium Aluminide: The European IMPRESS Project", International Journal of Thermophysics 28, pp. 1026-1036, 2007.

[15] S. McFadden, D.J. Browne, "A front-tracking model to predict solidification macrostructures and columnar to equiaxed transitions in alloy castings", Applied Mathematical Modelling 33, pp. 1397-1416, 2009.

[16] V.T. Witusiewicz, A.A. Bondar, U. Hecht and T.Ya. Velikanova, "The Al-B-Nb-Ti system IV. Experimental study and thermodynamic re-evaluation of the binary Al-Nb and ternary $\mathrm{Al}-\mathrm{Nb}-\mathrm{Ti}$ systems", Journal of Alloys and Compounds 472, pp. 133-161, 2009.

[17] N. Saunders, "TiAl data, thermodynamic database for calculation of phase equilibria in multicomponent TiAl alloys". Guilford, Thermotech Ltd. Surrey Technology Centre, 2007.

[18] V.T. Witusiewicz, A.A. Bondar, U. Hecht et al., "The Al-B-Nb-Ti system $\mathrm{V}$. Thermodynamic description of the ternary system Al-B-Ti”, Journal of Alloys and Compounds 474, pp. 86-104, 2009. 
[19] J. Eiken, M. Apel, V.T. Witusiewicz, J. Zollinger, U. Hecht, "Interplay between $\alpha(\mathrm{Ti})$ nucleation and growth during peritectic solidification investigated by phase-field simulations", Journal of Physics: Condensed Matter 46, pp. 464104-464110, 2009.

[20] A. Kartavykh, V. Ginkin, S. Ganina et al., "Numerical study of convection-induced peritectic macro-segregation effect at the directional counter-gravity solidification of Ti-46Al-8Nb alloy”, Intermetallics 19, pp. 769-775, 2011.

[21] A. Kartavykh, V. Ginkin, S. Ganina et al., "Convectioninduced peritectic macro-segregation proceeding at the directional solidification of Ti-46Al-8Nb intermetallic alloy", Materials Chemistry and Physics 126, pp. 200-206, 2011. 